\title{
Psychological Stress and Arterial Stiffness in Korean Americans
}

Jeongok G Logan, Ph.D, RN,

School of Nursing, University of North Carolina at Chapel Hill

Debra J Barksdale, Ph.D, RN, FNP-BC, FAANP [Associate Professor],

School of Nursing, University of North Carolina at Chapel Hill

John Carlson, MS [Research Associate Professor],

School of Nursing, University of North Carolina at Chapel Hill

Barbara W Carlson, Ph.D, RN [Associate Professor], and

School of Nursing, University of North Carolina at Chapel Hill

Pamela J Rowsey, Ph.D, RN [Associate Professor]

School of Nursing, University of North Carolina at Chapel Hill

\section{Abstract}

Objective-Arterial stiffness is identified as a causative factor for hypertension. The purpose of this study was to explore the relationship between psychological stress and arterial stiffness in Korean Americans.

Methods-A convenience sample of 102 Korean Americans (aged 21-60 years, 60\% women) was recruited from North Carolina. Psychological stress was measured by the Perceived Stress Scale, the Social, Attitudinal, Familiar, and Environmental (SAFE) Acculturative Stress Scale, and the Spielberger's State-Trait Anxiety Inventory. Arterial stiffness was measured by carotidfemoral pulse wave velocity (cfPWV) using the SphygmoCor system (AtCor Medical, Australia).

Results-This study shows that the emotional stress response, measured by anxiety, significantly predicted arterial stiffness $(\beta=.25, \mathrm{p}=.008)$, independently of such confounding factors as age, mean arterial pressure (MAP), gender, body mass index, smoking, education, and income. Anxiety was neither related to age $(\mathrm{r}=.12, \mathrm{p}=.212)$ nor MAP $(\mathrm{r}=.14, \mathrm{p}=.151)$. Additionally, this sample of Korean Americans had higher levels of psychological stress when compared to previous findings from studies of other racial/ethnic groups in the U.S.

Conclusion-Findings demonstrate that anxiety is a significant and independent determinant of arterial stiffness. Given that anxiety was not related to MAP, these findings suggest that arterial stiffness may be a pathway to explain the connection between anxiety and hypertension risk. Studies that scrutinize the relationship between anxiety and arterial stiffness are an important next step for future research. Further studies are also recommended to explore cultural factors and individual characteristics that may affect anxiety in Korean Americans.

(C) 2012 Elsevier Inc. All rights reserved.

Corresponding Author: Dr. Jeongok G Logan, Ph.D, RN, School of Nursing, University of North Carolina at Chapel Hill.

Publisher's Disclaimer: This is a PDF file of an unedited manuscript that has been accepted for publication. As a service to our customers we are providing this early version of the manuscript. The manuscript will undergo copyediting, typesetting, and review of the resulting proof before it is published in its final citable form. Please note that during the production process errors may be discovered which could affect the content, and all legal disclaimers that apply to the journal pertain. 


\section{INTRODUCTION}

Arterial stiffness has been identified as an independent marker of cardiovascular morbidity and mortality $(1,2)$. Traditionally, it was believed that arterial stiffness was the result of hypertension (3, 4). However, population-based longitudinal studies have shown that arterial stiffness may itself predict progression to hypertension in nonhypertensive subjects $(5,6)$.

It is well accepted that psychological stress contributes to elevated blood pressure and to the development of hypertension and other cardiovascular diseases (CVD). The mechanisms by which stress increases CVD risks include its effects on the sympathetic nervous system, rennin-angiotensin system, inflammation, cortisol levels, and unhealthy behaviors (7-10). Since arterial stiffness is now considered a causative factor for hypertension, it is plausible that psychological stress may contribute to arterial stiffness before hypertension is manifested (6).

Research suggests that acute psychological stress induced in laboratory environments increases arterial stiffness (11-14). However, only a few studies have explored the relationship between real life psychological stress and arterial stiffness, and for those that have, their findings are contradictory $(15,16)$, with very few having enough subjects to explain this relationship in different racial/ethnic groups.

Several studies have reported that Korean Americans may experience high levels of emotional distress from trying to adapt to the social, cultural, and economic norms of a new society (17-22). Moreover, Korean Americans have a higher prevalence of hypertension (32\%) as compared to Koreans in Korea (23). Thus, Korean Americans are a vulnerable population at high risk for both stress and hypertension.

The purpose of this study was to explore the relationship between psychological stress and arterial stiffness in Korean Americans. This study examined the correlation between psychological stress (as operationalized by perceived stress, acculturative stress, and anxiety) and arterial stiffness in Korean Americans, and how much of the variance in their arterial stiffness was accounted for by psychological stress, after controlling for blood pressure, age, gender, body mass index, smoking status, education and income.

\section{METHODS}

\section{Participants}

After Institutional Review Board (IRB) approval, 102 Korean American males and females were recruited from three counties in North Carolina. Inclusion criteria included being 2160 years of age, being born in Korea, having lived in the US for at least 1 year, and able to read and speak Korean. Subjects learned about the study from flyers and by word of mouth.

People who had an irregular cardiac rhythm (e.g., frequent premature atrial contractions or premature ventricular contractions) were excluded since the method used to measure arterial stiffness (SphygmoCor, AtCor Medical, Australia) requires a regularly occurring pulse wave and ECG waveform to derive its measures. Antihypertensive medications may cause muscular artery dilation that results in decreased pulse wave velocity (24). Therefore, people who were taking antihypertensive medications or other medications known to affect blood pressure (e.g., $\beta$-blockers, thyroid, hormones, or steroids) were also excluded from the study. Those with known cardiac conditions (e.g., pace maker, heart failure, coronary artery disease, myocardial infarction, left ventricular dysfunction, or valvular heart diseases), known vascular conditions (e.g., peripheral vascular diseases), and those individuals who 
were currently taking medications for a mental disorder (e.g., schizophrenia or major affect disorders) that may affect the measures of perceived stress were also excluded.

\section{Measures}

The study measured psychological stress, physiological factors (arterial stiffness and blood pressure), and contextual factors (age, gender, body mass index, smoking status, education, income, marital status, and occupation).

Psychological Stress-In this study, psychological stress included both cognitive and emotional stress. Cognitive stress was operationalized as perceived stress - a global measure of life stress, and acculturative stress - the stress from trying to adapt to a different culture (25). Anxiety was also assessed as a measure of the emotional response to stressful life events (26).

Perceived Stress was measured with the Perceived Stress Scale (PSS), a widely used instrument for measuring the degree to which situations in one's life are appraised as stressful (27). A 5-point Likert scale ranging from 0="never" to 4="very often" was used and scores were derived from the sum of the item scores, with higher scores indicating greater stress. Among the 4,10, and 14-item versions, the 10-item version used in this study has shown maximum reliability $(28,29)$. The 10 -item Perceived Stress Scale (PSS) has good internal consistency (Cronbach's alpha $=0.85)$, test retest reliability $(r=.85)(27)$, construct validity and predictive validity (30). In this study, the Korean version of the scale's internal consistency was Cronbach's alpha 0.83 and its test - retest reliability with a two week interval was .79.

Acculturative stress was measured with the modified short version of the original 60 item SAFE scale (31). This 24-item version of the Revised SAFE scale (R-SAFE) comprises 17

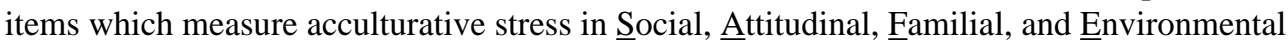
contexts (31) and 7 items that measure "perceived discrimination or majority group stereotypes toward immigrant populations" (32). The R-SAFE scale has been used in 4, 5, or 6-point Likert scales in different studies (33-35). In this study, a 4-point Likert scale ranging from $0=$ "not stressful" to $3=$ "extremely stressful" was used and scores were derived from the sum of the item scores with higher scores indicating greater acculturative stress. The RSAFE has good construct validity (32) and convergent and discriminant validity (36). Possible scores range from 0 to 72 . Studies reported that the R-SAFE is also reliable for Asian Americans (Cronbach's alpha .89) (37). In the present study, the Korean version of the scale showed good internal consistency (Cronbach's alpha .88) and good test - retest reliability within a two week interval $(\mathrm{r}=.73)$.

Anxiety was measured by the Spielberger State-Trait Anxiety Inventory (STAI). The 40 item 4-point Likert scale was developed to measure anxiety in adults. The first subscale measures state anxiety, and the second subscales measures trait anxiety (38). Total scores obtained from the subscales range from 20 to 80 with higher scores indicating greater anxiety. This scale has been used extensively in practice demonstrating good construct and divergent validity and test- retest reliability $(38,39)$. In this study, the internal consistency of the STAI was very good; Cronbach's a was .93 for state anxiety and .93 for trait anxiety).

Korean versions of the 10-item PSS and the 24-item version of the R-SAFE were not available. Therefore, these two scales were translated to Korean according to Brislin's translation model (40). The principal investigator (PI), who was sensitive to Korean subjects' cultural nuances, translated them into Korean. A bilingual Korean reviewed the initially translated version and back translated them into English. An American professor, who was familiar with the American version of the scale, compared the original scale with 
the back translated English version of the scale. Based on the results of this comparison, the Korean version of the scale was refined. These processes were repeated until the original scale was judged equivalent to the back translated English version of the scale by the American professor.

Physiological Factors-Arterial stiffness was measured using the SphygmoCor device (AtCor Medical, Australia). A pressure sensitive transducer (tonometer) was applied on carotid and femoral sites to measure the time for pulse waves to reach these two sites. The distance that the pulse wave travels is determined by measuring the distance from the suprasternal notch to the carotid artery site ( $d$-carotid) and the distance from the suprasternal notch to the femoral artery site ( $d$-femoral) using a standard tape measure. The time from the $\mathrm{R}$ wave on the electrocardiogram to the foot of the carotid pulse waveform $\left(\mathrm{t}_{1}\right)$ and the foot of the femoral arterial waveform $\left(\mathrm{t}_{2}\right)$ are measured in order to derive the mean time difference for the pulse wave to reach the two sites (Figure 1). The resulting measure (the carotid-femoral pulse wave velocity or cf-pwv) is the difference in the two distances, from suprasternal notch to two arterial sites $\left(\mathrm{dpwv}=\mathrm{d}_{\text {femoral }}-\mathrm{d}_{\text {carotid }}\right)$, divided by the mean time difference between $t_{1}$ and $t_{2}$. Thus, the cf-pwv reflects the speed of the pressure wave as it travels through the aorta, in meters per second $(\mathrm{m} / \mathrm{s})$. The higher the carotid-femoral pulse wave velocity, the stiffer the vessel. Reference values for carotid-femoral pulse wave velocity were established in a previous study of 1455 people aged 15 to 59 years with normal blood pressures and ranged from 6.2 to $8.3 \mathrm{~m} / \mathrm{s}$. (41)

Blood Pressure (BP) is a measure of the force applied to the walls of the arteries as the heart pumps blood through the body in millimeters of mercury (42). Systolic, diastolic, and mean arterial blood pressures were measured at the brachial artery, with subject in the supine position, using the WelchAllyn Vital Signs Monitor 300 Series (USA). An incorrect cuff size could result in erroneous BP measurements (43); thus, the mid-section circumference of the dominant upper arm was determined with a measuring tape, and the proper sized cuff was selected according to the upper arm circumference. The bladder of the cuff should encircle at least $80 \%$ of the arm. The cuff was placed over the bare arm to maximize reliability of the measures. The artery marker on the cuff was placed over the brachial artery and the cuff was applied snuggly allowing no more than two fingers underneath. The arm was kept at the level of the heart without movement and the subjects were not spoken to and were asked not to speak during the BP measurement (44). Using the automated BP monitoring device, $\mathrm{BP}$ was measured twice in the dominant arm with a 2 minutes rest between measures (45).

Contextual Factors-Age, gender, smoking status, education, income, marital status, and occupation were self-reported. Height in centimeters was measured with a portable stadiometer (Accu-Hite, USA), and weight in kilograms was measured with an electronic scale (Penn Scale, USA), these two measures were used to determined body mass index (BMI) in kilograms $/$ meter squared $\left(\mathrm{kg} / \mathrm{m}^{2}\right)$.

\section{Procedures}

Arterial stiffness tends to be higher in the morning than in the evening (46) and is responsive to factors that alter heart rate and blood pressure. To minimize potential confounders, all the measures were performed in the morning between 7 and $11 \mathrm{am}$, and subjects were instructed to refrain from consuming coffee, smoking, and eating for at least 3 hours and from drinking alcohol for at least 10 hours before data collection (2). After obtaining informed consent, demographic information, height, and weight from the participants, they completed three psychological stress scales (the Perceived Stress scale, the Revised SAFE scale, and the Spielberger State-Trait Anxiety inventory) in Korean. After finishing the three scales, 
participants rested at least 10 minutes in the recumbent position and blood pressure was measured twice with a 2 minutes rest between measures. Afterwards, pulse wave velocity $(\mathrm{PWV})$ was measured by investigators who were well-trained in using the SphygmoCor device. The procedure for measuring PWV complied with the European Society of Cardiology's recommendation to standardize subject conditions when measuring arterial stiffness (2).

\section{Data analysis}

All analyses were performed with SAS (version 9.1 for Windows, SAS Institute Inc, NC, USA). Correlations were used to examine the relationships between each psychological stress variable and arterial stiffness. Multiple regression analysis was used to determine how much of the variance in arterial stiffness was explained by psychological stress, controlling for confounding factors that were significantly correlated with arterial stiffness. Possible multicollinearity among independent variables in the multiple regressions was examined by the variance inflation factor (VIF), eigenvectors among the predictors, and partial correlations. A high level of correlation between state anxiety and trait anxiety was reflected in non-negligible multicollinearity; therefore, one factor (anxiety) was created by a principal components analysis and used as an independent variable in the multiple regressions. Systolic blood pressure (SBP) and diastolic blood pressure (DBP) were also highly correlated with each other; therefore, mean arterial pressure (MAP) was used to represent blood pressure in the multiple regressions. Statistical significance was set at a p-value less than 0.05 . To examine the internal consistency and test-retest reliability of the Korean version of the scales, Cronbach's alpha and Pearson product moment correlations were examined.

\section{RESULTS}

Participants included 102 Korean Americans; women comprised 60\% of the sample. Age ranged from 21 to 60 years; the mean age for both men and women was similar, men 39.76 (SD 9.71) and women 38.96 (SD 10.44). BMI ranged from 16.4 to $31.6 \mathrm{~kg} / \mathrm{m}^{2}$, with a mean of $23.6 \mathrm{~kg} / \mathrm{m}^{2}$ (SD 3.2). Over one half (67.6\%) of the sample had 4-years of college or higher education and $21.6 \%$ of the sample were high school graduates. More than half $(65.7 \%)$ reported a household income of less than $\$ 49,999$ per year and only $21.6 \%$ of the sample had a household income greater than $\$ 75,000$. Most $(71.6 \%)$ of the sample lived with their spouse. Just over a third of the sample (34.31\%) had professional occupations, $17 \%$ were home makers, and $15 \%$ were laborers. Only $6 \%$ of the sample were current smokers.

Table 1 presents the descriptive statistics for the psychological and physiological variables. All psychological and physiological variables except SBP were normally distributed. SBP had moderate kurtosis. According to the seventh report of the Joint National Committee (47), more than half $(53.92 \%)$ of the sample was classified as having normal BP, while $36.27 \%$ were prehypertensive and $9.8 \%$ were hypertensive.

The three indicators of psychological stress (perceived stress, acculturative stress, and state and trait anxiety) were significantly related to each other. For example, perceived stress was related to accultuative stress $(\mathrm{r}=.39, \mathrm{p}<.001)$, state anxiety $(\mathrm{r}=.49, \mathrm{p}<.001)$, and trait anxiety $(\mathrm{r}=.49, \mathrm{p}<.001)$. Acculturative stress was associated with state anxiety $(\mathrm{r}=.40, \mathrm{p}<.001)$ and trait anxiety $(\mathrm{r}=.44, \mathrm{p}<.001)$.

Arterial stiffness was associated with many well-known factors related to hypertension. Specifically, higher levels of arterial stiffness were associated with higher age $(r=.61, \mathrm{p}<$. $001)$ and body mass index $(r=.28, p=.005)$. Arterial stiffness was negatively associated with 
education $(\mathrm{r}=-.35, \mathrm{p}<.001)$ but not with income, and did not differ by gender or smoking status. Lastly, higher arterial stiffness was also associated with higher $\operatorname{SBP}(r=.45 . p<.001)$, $\operatorname{DBP}(\mathrm{r}=.56, \mathrm{p}<.001)$, and MAP $(\mathrm{r}=.54, \mathrm{p}<.001)$.

The correlations of arterial stiffness and BP with psychological stress variables are shown in Table 2. While arterial stiffness was not related to perceived stress, it was significantly related to acculturative stress, state anxiety, and trait anxiety. SBP was related to acculturative stress and state anxiety but their relationships were marginally significant. DBP was not significantly related to any of psychological variables.

Table 3 shows the results of a multiple linear regression analysis. The significant bivariate relationships of education, BMI, and acculturative stress with arterial stiffness disappeared in the multivariate analysis. Education was correlated with age $(\mathrm{r}=-.33, \mathrm{p}<.001)$ and MAP $(\mathrm{r}=-.33, \mathrm{p}<.001)$ in the bivariate analysis. When the effect of age and MAP were partialled out from the relationship between education and arterial stiffness, education was no longer correlated with arterial stiffness $(\mathrm{r}=-.10, \mathrm{p}=.322)$. Acculturative stress was also correlated with age $(\mathrm{r}=.32, \mathrm{p}=.001)$ in the bivariate analysis, but the relationship between acculturative stress and arterial stiffness was also no longer significant when age was partialled out $(r=$. $01, \mathrm{p}=.927)$. BMI was correlated with MAP $(\mathrm{r}=.28, \mathrm{p}=.004)$. When the effect of MAP was removed, BMI was not related to arterial stiffness $(\mathrm{r}=.16, \mathrm{p}=.119)$. Anxiety was neither correlated with age $(\mathrm{r}=.12, \mathrm{p}=.212)$ nor with MAP $(\mathrm{r}=.14, \mathrm{p}=.151)$. The multiple regression result showed that age, MAP, and anxiety were significant independent predictors of arterial stiffness after controlling for age, MAP, education, BMI, and acculturative stress.

\section{DISCUSSION}

This study shows that emotional stress measured by anxiety significantly predicted arterial stiffness as measured by cfPWV. This finding is noteworthy because the effect of anxiety on arterial stiffness was independent of age, MAP, education, BMI, and acculturative stress. Although arterial stiffness was identified as a preexisting condition that precedes the development of hypertension, transient stiffening of the large arteries occurs when arterial BP rises (4). Age is also a powerful determinant of arterial stiffness (48). Therefore, it is important to control for BP and age when the independent effects of predictors on arterial stiffness were assessed. Partial correlation results showed that the relationships of education, BMI, and acculturative stress with cfPWV were no longer significant when MAP and age were partialled out, suggesting that their relationships with cfPWV were confounded by MAP and age. However, anxiety was neither related to age nor MAP, and still significantly related to cfPWV after controlling for age and MAP. Given that arterial stiffness is identified as a causative factor for hypertension, this finding suggests that arterial stiffness may be a pathway to explain the connection between anxiety and hypertension risk.

Previous studies have reported inconsistent and contradictory results on the relationship between anxiety and arterial stiffness. For example, one study that compared arterial stiffness measured by brachial and ankle PWV (baPWV) in 25 patients diagnosed with anxiety disorder with 23 age- and sex matched controls (all subjects were East Asian) reported that baPWV was significantly higher in the anxiety patient group (49). Another study with 156 Black and White Americans also showed that trait anxiety was associated with arterial stiffness measured by cfPWV. Interestingly, this relationship was significant only in Blacks, showing the interaction between the effects of anxiety and race on cfPWV(50). On the other hand, the Health, Aging, and Body Composition Study with 2,488 older adults (60\% White and $40 \%$ Black) reported that anxiety symptoms measured by the Hopkins Symptom Checklist were not related to cfPWV (51). In another study conducted with 382 Japanese males aged 24 to 39 years, tension and anxiety were measured by the 
Profile of Mood States (POMS), and arterial stiffness by brachial-ankle PWV. That study showed that neither tension nor anxiety was related to arterial stiffness (52). Possible reasons for the inconsistent results may include the use of different measures for anxiety.

The relationship between anxiety and arterial stiffness demonstrated in this study may be mediated by autonomic function $(49,53)$. Anxiety may induce an increase of sympathetic function, and a decrease of parasympathetic function $(54,55)$. Dysregulation of autonomic function may also be connected to increased arterial stiffness $(49,54,56)$. A few previous studies have investigated associations between autonomic function and arterial stiffness in physically healthy adults. For example, one study with 382 Japanese males (age 24 to 39 years) reported that arterial stiffness measured by brachial-ankle pulse wave velocity (baPWV) was related to Low Frequency /High Frequency ratio (LF/HF ratio) of Heart Rate Variability (HRV). This relationship remained significant after controlling for age, blood pressure (BP), and plasma noradrenalin levels, suggesting that arterial stiffness is related to increased sympathetic activity (52). In another study with 23 healthy participants (mean age 45 years) and 25 patients with anxiety disorder (mean age 45 years), baPWV did not have any relationship to LF/HF ratio, but was negatively related to HF only in patients with anxiety disorder (49), suggesting increased arterial stiffness and reduced vagal tone in people with anxiety disorders.

Another notable finding of this study is the levels of psychological stress in Korean Americans. Higher incidences of psychological problems have been observed in immigrant populations compared to dominant cultural groups (57-59). Several studies previously reported high levels of psychological stress, anxiety, and depression in Korean Americans $(17,19,20)$. Similarly, this sample of Korean Americans had high levels of psychological stress. Specifically, the mean score of perceived stress scale (16.59) was higher than the reference levels from 2,387 respondents in the U.S.: Whites (12.8), Hispanics (14.0), and Blacks (14.7), and for all other minority groups combined (14.1) (Cohen et al., 1983; 1988; 1994). Direct comparisons of the levels of acculturative stress found in this study with the levels reported in previous studies were not possible because different versions of the SAFE scale or different Likert scales were used (e.g. 17 items (60); 5-point Likert scale $(33,34)$; and 6-point Likert scale (35)). The mean levels of state anxiety (36.06) and trait anxiety (39.62) in this sample were higher than the mean (33.5 for both state and trait anxiety) reported for 222 adults (whites $71.6 \%$, Blacks $17.6 \%$, and others $3.9 \%$ ) that had clinically diagnosed chronic health failure (61).

Previous studies have clearly demonstrated that acculturative stress exerts an influence on anxiety symptoms (62-64). Although the present study did not show the independent effect of acculturative stress on arterial stiffness, the significant associations among three indicators of psychological stress (perceived stress, acculturative stress, and state and trait anxiety) imply that acculturative stress may increase the risk of arterial stiffness through its impact on anxiety in this immigrant population. Further studies are recommended to explore cultural factors and individual characteristics that may hinder the acculturation process and increase psychological problems in Korean Americans.

This study has several potential limitations. First, the sample was relatively small, homogenous, and recruited from a limited geographical region (three contiguous counties) of North Carolina. Since most of the study participants were recruited from churches, their level of stress may be different from other Korean Americans who are not affiliated with religious organizations. Secondly, all psychological variables were self-reported. In the Korean culture, people may be reluctant to share their personal information with researchers. Therefore, responses may be based on what is perceived as socially desirable (67). Thirdly, the design of this study was cross-sectional. In order to confirm directionality of 
relationships between identified risk factors and physiological variables, longitudinal studies should be conducted. Lastly, there are many other factors that may influence BP and arterial stiffness. For example, lack of exercise and poor diet are very important risk factors for CVD but they were not measured in this study. In order to examine independent effects of identified predictors on blood pressure and arterial stiffness, further studies are recommended to include other important factors.

In conclusion, the emotional aspect of psychological stress measured by state and trait anxiety significantly predicted arterial stiffness as measured by cfPWV, independent of age and MAP which are major determinants of arterial stiffness. Since trait anxiety was not significantly related to BP and state anxiety was marginally positively associated with SBP, this may suggest that arterial stiffness may be a pathway to explain the connection between anxiety and hypertension risk. In addition, results from this study indicate that Korean Americans may have high levels of psychological stress. Additional studies are suggested to examine factors contributing to anxiety in Korean Americans and to better understand the connection between anxiety and arterial stiffness and the potential role of decreased cardiac vagal activities in mediating anxiety and arterial stiffness. The hope is that future studies will address interventions for stress relief and early detection and/or reduction of arterial stiffness, before hypertension and cardiovascular complications develop.

\section{References}

1. Cohn JN, Duprez DA, Grandits GA. Arterial elasticity as part of a comprehensive assessment of cardiovascular risk and drug treatment. Hypertension. $2005 \mathrm{Jul}$; 46(1):217-20. [PubMed: 15867132]

2. Laurent S, Cockcroft J, Van Bortel L, Boutouyrie P, Giannattasio C, Hayoz D, Pannier B, Vlachopoulos C, Wilkinson I, Struijker-Boudier H. Expert consensus document on arterial stiffness: methodological issues and clinical applications. Eur Heart J. 2006 Nov; 27(21):2588-605. [PubMed: 17000623]

3. Risler NR, Cruzado MC, Miatello RM. Vascular remodeling in experimental hypertension. ScientificWorldJournal. 2005 Dec 12.5:959-71. [PubMed: 16362087]

4. Franklin SS. Arterial stiffness and hypertension: a two-way street? Hypertension. 2005 Mar; 45(3): 349-51. [PubMed: 15710783]

5. Dernellis J, Panaretou M. Aortic stiffness is an independent predictor of progression to hypertension in nonhypertensive subjects. Hypertension. 2005 Mar; 45(3):426-31. [PubMed: 15710784]

6. Liao D, Arnett DK, Tyroler HA, Riley WA, Chambless LE, Szklo M, Heiss G. Arterial stiffness and the development of hypertension. The ARIC study. Hypertension. 1999 Aug; 34(2):201-6. [PubMed: 10454441]

7. Steptoe A, Melville D, Ross A. Essential hypertension and psychological functioning: a study of factory workers. Br J Clin Psychol. 1982 Nov; 21(Pt 4):303-11. [PubMed: 7171882]

8. Rozanski A, Blumenthal JA, Kaplan J. Impact of psychological factors on the pathogenesis of cardiovascular disease and implications for therapy. Circulation. 1999 Apr 27; 99(16):2192-217. [PubMed: 10217662]

9. Ghiadoni L, Donald AE, Cropley M, Mullen MJ, Oakley G, Taylor M, O’Connor G, Betteridge J, Klein N, Steptoe A, Deanfield JE. Mental stress induces transient endothelial dysfunction in humans. Circulation. 2000 Nov 14; 102(20):2473-8. [PubMed: 11076819]

10. Rozanski A, Blumenthal JA, Davidson KW, Saab PG, Kubzansky L. The epidemiology, pathophysiology, and management of psychosocial risk factors in cardiac practice: the emerging field of behavioral cardiology. J Am Coll Cardiol. 2005 Mar 1; 45(5):637-51. [PubMed: 15734605]

11. Tabara Y, Kohara K, Nakagawa S, Handa J, Hayashi M, Hamada C, Miyaguchi M, Shigemi Y, Miki T, Konishi M. Effects of obesity and smoking on mental stress-induced blood pressure and augmentation index responses in normotensive young males: the J-SHIPP study. Hypertens Res. 2008 Jun; 31(6):1219-24. [PubMed: 18716371] 
12. Vlachopoulos C, Kosmopoulou F, Alexopoulos N, Ioakeimidis N, Siasos G, Stefanadis C. Acute mental stress has a prolonged unfavorable effect on arterial stiffness and wave reflections. Psychosom Med. 2006 Mar-Apr;68(2):231-7. [PubMed: 16554388]

13. Lipman RD, Grossman P, Bridges SE, Hamner JW, Taylor JA. Mental stress response, arterial stiffness, and baroreflex sensitivity in healthy aging. J Gerontol A Biol Sci Med Sci. 2002 Jul; 57(7):B279-84. [PubMed: 12084798]

14. Vlachopoulos C, Xaplanteris P, Alexopoulos N, Aznaouridis K, Vasiliadou C, Baou K, Stefanadi E, Stefanadis C. Divergent effects of laughter and mental stress on arterial stiffness and central hemodynamics. Psychosom Med. 2009 May; 71(4):446-53. [PubMed: 19251872]

15. Nomura K, Nakao M, Karita K, Nishikitani M, Yano E. Association between work-related psychological stress and arterial stiffness measured by brachial-ankle pulse-wave velocity in young Japanese males from an information service company. Scand J Work Environ Health. 2005 Oct; 31(5):352-9. [PubMed: 16273961]

16. Utsugi M, Saijo Y, Yoshioka E, Sato T, Horikawa N, Gong Y, Kishi R. Relationship between two alternative occupational stress models and arterial stiffness: a cross-sectional study among Japanese workers. Int Arch Occup Environ Health. 2009 Jan; 82(2):175-83. [PubMed: 18365237]

17. Chun M, Knight BG, Youn G. Differences in stress and coping models of emotional distress among Korean, Korean-American and White-American caregivers. Aging Ment Health. 2007 Jan; 11(1):20-9. [PubMed: 17164154]

18. Kim MT, Han HR, Shin HS, Kim KB, Lee HB. Factors associated with depression experience of immigrant populations: a study of Korean immigrants. Arch Psychiatr Nurs. 2005 Oct; 19(5):21725. [PubMed: 16226673]

19. Koh KB. Perceived stress, psychopathology, and family support in Korean immigrants and nonimmigrants. Yonsei Med J. 1998 Jun; 39(3):214-21. [PubMed: 9664825]

20. Kuo WH. Prevalence of depression among Asian-Americans. J Nerv Ment Dis. 1984 Aug; 172(8): 449-57. [PubMed: 6747614]

21. Shin KR. Factors predicting depression among Korean-American women in New York. Int J Nurs Stud. 1993 Oct; 30(5):415-23. [PubMed: 8225807]

22. Saint Arnault D, Kim O. Is there an Asian idiom of distress? Somatic symptoms in female Japanese and Korean students. Arch Psychiatr Nurs. 2008 Feb; 22(1):27-38. [PubMed: 18207054]

23. Korea National Statistical Office. Korean People Health and Nutrition Survey. 2001. Retrieved from http://www.kosis.kr/

24. O'Rourke MF, Nichols WW, O'Brien E. Effects of ramipril on arterial stiffness. Hypertension. 2005 Oct.46(4):e14. author reply e-5. [PubMed: 16195488]

25. Berry, JW. Acculturative stress. In: Lonner, WJ.; Malpass, RS., editors. Psychology and Culture. Boston: Allyn \& Bacon; 1994. p. 211-215.

26. Lazarus, RS. Stress and emotion : a new synthesis. New York: Springer Pub. Co; 1999.

27. Cohen S, Kamarck T, Mermelstein R. A global measure of perceived stress. J Health Soc Behav. 1983 Dec; 24(4):385-96. [PubMed: 6668417]

28. Monroe, S.; Kelley, J. Measurement of Stress Appraisal. In: Cohen, S.; Kessler, R.; Underwood Gordon, L., editors. Measuring Stress. New York: Oxford University Press; 1995. p. 122-147.

29. Cohen, S.; Kessler, R.; Underwood Gordon, L. Measuring Stress: A Guide for Health and Social Scientists. New York: Oxford University Press; 1995.

30. Cohen S, Tyrrell DA, Smith AP. Negative life events, perceived stress, negative affect, and susceptibility to the common cold. J Pers Soc Psychol. 1993 Jan; 64(1):131-40. [PubMed: 8421249]

31. Padilla AM, Wagatsuma Y, Lindholm KJ. Acculturation and personality as predictors of stress in Japanese and Japanese-Americans. J Soc Psychol. 1985 Jun; 125(3):295-305. [PubMed: 4079350]

32. Mena FJ, Padilla AM, Maldonado M. Acculturative stress and specific coping strategies among immigrant and later generation college students. Hispanic Journal of Behavioral Sciences. 1987; 9:207-25.

33. Hovey JD. Acculturative stress, depression, and suicidal ideation in Mexican immigrants. Cultur Divers Ethnic Minor Psychol. 2000 May; 6(2):134-51. [PubMed: 10910528] 
34. Walker RL, Wingate LR, Obasi EM, Joiner TE. An empirical investigation of acculturative stress and ethnic identity as moderators for depression and suicidal ideation in college students. Cultur Divers Ethnic Minor Psychol. 2008 Jan; 14(1):75-82. [PubMed: 18230003]

35. Amer, MM. A Dissertation. The University of Toledo; 2005. Arab American Mental Health in the Post September 11 Era: Accultuation, Stress and Coping.

36. Joiner TE Jr, Walker RL. Construct validity of a measure of acculturative stress in African Americans. Psychol Assess. 2002 Dec; 14(4):462-6. [PubMed: 12501571]

37. Kim MJ, Ahn YH, Chon C, Bowen P, Khan S. Health disparities in lifestyle choices among hypertensive Korean Americans, non-Hispanic Whites, and Blacks. Biol Res Nurs. 2005 Jul; 7(1): 67-74. [PubMed: 15920004]

38. Spielberger, CD.; Gorsuch, RL.; Lushene, RE.; Jacobs, GA. State-Trait Anxiety Inventory in Adults. CA: Consulting Psychologists Press; 1983.

39. Oner, N.; Le Comple, A. State-Trait Anxiety Inventory Handbook. Istanbul: Bongazici University Publications; 1985.

40. Jones PS, Lee JW, Phillips LR, Zhang XE, Jaceldo KB. An adaptation of Brislin's translation model for cross-cultural research. Nurs Res. 2001 Sep-Oct;50(5):300-4. [PubMed: 11570715]

41. EHJ. Determinants of pulse wave velocity in healthy people and in the presence of cardiovascular risk factors: 'establishing normal and reference values'. Eur Heart J. 2010 Oct; 31(19):2338-50. [PubMed: 20530030]

42. Levy, MN.; Pappano, AJ.; Berne, RM. Cardiovascular physiology. 9. Philadelphia, PA: Mosby/ Elsevier; 2007.

43. Maxwell MH, Waks AU, Schroth PC, Karam M, Dornfeld LP. Error in blood-pressure measurement due to incorrect cuff size in obese patients. Lancet. 1982 Jul 3; 2(8288):33-6. [PubMed: 6123760]

44. Umana E, Ahmed W, Fraley MA, Alpert MA. Comparison of oscillometric and intraarterial systolic and diastolic blood pressures in lean, overweight, and obese patients. Angiology. 2006 Jan-Feb;57(1):41-5. [PubMed: 16444455]

45. Pickering TG, Hall JE, Appel LJ, Falkner BE, Graves J, Hill MN, Jones DW, Kurtz T, Sheps SG, Roccella EJ. Recommendations for blood pressure measurement in humans and experimental animals: part 1: blood pressure measurement in humans: a statement for professionals from the Subcommittee of Professional and Public Education of the American Heart Association Council on High Blood Pressure Research. Circulation. 2005 Feb 8; 111(5):697-716. [PubMed: 15699287]

46. Papaioannou TG, Karatzis EN, Papamichael CM, Karatzi KN, Zakopoulos NA, Lekakis JP, Mavrikakis M, Stefanadis C. Circadian variation of arterial pressure wave reflections. Am J Hypertens. 2006 Mar; 19(3):259-63. [PubMed: 16500510]

47. Chobanian AV, Bakris GL, Black HR, Cushman WC, Green LA, Izzo JL Jr, Jones DW, Materson BJ, Oparil S, Wright JT Jr, Roccella EJ. Seventh report of the Joint National Committee on Prevention, Detection, Evaluation, and Treatment of High Blood Pressure. Hypertension. 2003 Dec; 42(6):1206-52. [PubMed: 14656957]

48. Lee HY, Oh BH. Aging and arterial stiffness. Circ J. 2010 Nov; 74(11):2257-62. [PubMed: 20962429]

49. Yeragani VK, Tancer M, Seema KP, Josyula K, Desai N. Increased pulse-wave velocity in patients with anxiety: implications for autonomic dysfunction. J Psychosom Res. 2006 Jul; 61(1):25-31. [PubMed: 16813842]

50. Midei AJ, Matthews KA. Social relationships and negative emotional traits are associated with central adiposity and arterial stiffness in healthy adolescents. Health Psychol. 2009 May; 28(3): 347-53. [PubMed: 19450041]

51. Lewis TT, Sutton-Tyrrell K, Penninx BW, Vogelzangs N, Harris TB, Vaidean GD, Ayonayon HN, Kim L, Lakatta EG, Newman AB. Race, psychosocial factors, and aortic pulse wave velocity: the Health, Aging, and Body Composition Study. J Gerontol A Biol Sci Med Sci. 2010 Oct; 65(10): 1079-85. [PubMed: 20522528]

52. Nakao M, Nomura K, Karita K, Nishikitani M, Yano E. Relationship between brachial-ankle pulse wave velocity and heart rate variability in young Japanese men. Hypertens Res. 2004 Dec; 27(12): 925-31. [PubMed: 15894832] 
53. Watkins LL, Grossman P, Krishnan R, Sherwood A. Anxiety and vagal control of heart rate. Psychosom Med. 1998 Jul-Aug;60(4):498-502. [PubMed: 9710297]

54. Thayer JF, Friedman BH, Borkovec TD. Autonomic characteristics of generalized anxiety disorder and worry. Biol Psychiatry. 1996 Feb 15; 39(4):255-66. [PubMed: 8645772]

55. Yeragani VK, Pohl R, Berger R, Balon R, Ramesh C, Glitz D, Srinivasan K, Weinberg P. Decreased heart rate variability in panic disorder patients: a study of power-spectral analysis of heart rate. Psychiatry Res. 1993 Jan; 46(1):89-103. [PubMed: 8464959]

56. Williams JE, Din-Dzietham R, Szklo M. Trait anger and arterial stiffness: results from the Atherosclerosis Risk in Communities (ARIC) study. Prev Cardiol. 2006 Winter;9(1):14-20. [PubMed: 16407698]

57. Fazel M, Wheeler J, Danesh J. Prevalence of serious mental disorder in 7000 refugees resettled in western countries: a systematic review. Lancet. 2005 Apr 9-15; 365(9467):1309-14. [PubMed: 15823380]

58. Cuellar I, Bastida E, Braccio SM. Residency in the United States, subjective well-being, and depression in an older Mexican-origin sample. J Aging Health. 2004; 16(4):447-66. [PubMed: 15271265]

59. Claassen D, Ascoli M, Berhe T, Priebe S. Research on mental disorders and their care in immigrant populations: a review of publications from Germany, Italy and the UK. Eur Psychiatry. 2005 Dec; 20(8):540-9. [PubMed: 15963698]

60. Mena FJ, Padilla AM, Maldonado M. Acculturative stress and specific coping strategies among immigrant and later generation college students. Hispanic Journal of Behavioral Sciences. 1987; 9(2):207-25.

61. Jiang W, Kuchibhatla M, Cuffe MS, Christopher EJ, Alexander JD, Clary GL, Blazing MA, Gaulden LH, Califf RM, Krishnan RR, O'Connor CM. Prognostic value of anxiety and depression in patients with chronic heart failure. Circulation. 2004 Nov 30; 110(22):3452-6. [PubMed: 15557372]

62. Suarez-Morales L, Lopez B. The impact of acculturative stress and daily hassles on pre-adolescent psychological adjustment: examining anxiety symptoms. J Prim Prev. 2009 Jul; 30(3-4):335-49. [PubMed: 19408124]

63. Jang Y, Chiriboga DA. Living in a Different World: Acculturative Stress Among Korean American Elders. J Gerontol B Psychol Sci Soc Sci. 2009 Apr 3.

64. Hovey JD, Magana C. Acculturative stress, anxiety, and depression among Mexican immigrant farmworkers in the midwest United States. J Immigr Health. 2000 Jul; 2(3):119-31. [PubMed: 16228745]

65. Berry JW. Immigration, acculturation, and adaptation. Applied Psychology: An International Review. 1997; 46:5-34.

66. Shin, GW. Ethnic pride source of prejudice, discrimination. The Korea Herald. 2006 Aug. Retrieved from http://aparc.stanford.edu/news/

67. Horwitz SM, Prados-Torres A, Singer B, Bruce ML. The influence of psychological and social factors on accuracy of self-reported blood pressure. J Clin Epidemiol. 1997 Apr; 50(4):411-8. [PubMed: 9179099] 
Electrocardiogram

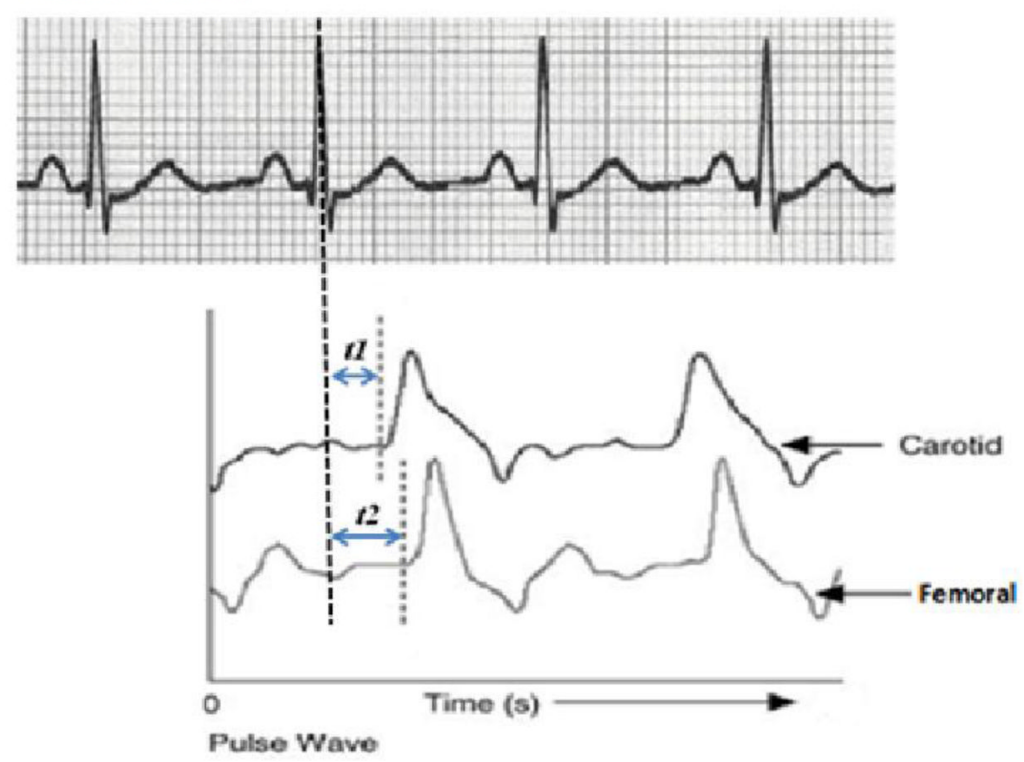

Figure 1.

Carotid and femoral Pulse Wave Velocity (cfPWV) Using the SphygmoCor

$t 1$ : The time difference between the R wave of EKG and the foot of carotid artery wave form $t 2$ : The time difference between the $\mathrm{R}$ wave of EKG and the foot of femoral artery wave form

$\Delta t$. The mean difference in time between A and B, taking the difference between $t 1$ and $t 2$ $d p w v$. The difference between $d$-femoral and $d$-carotid

$$
P W V=\frac{d_{P W V}}{\Delta t} \quad(m / s)
$$




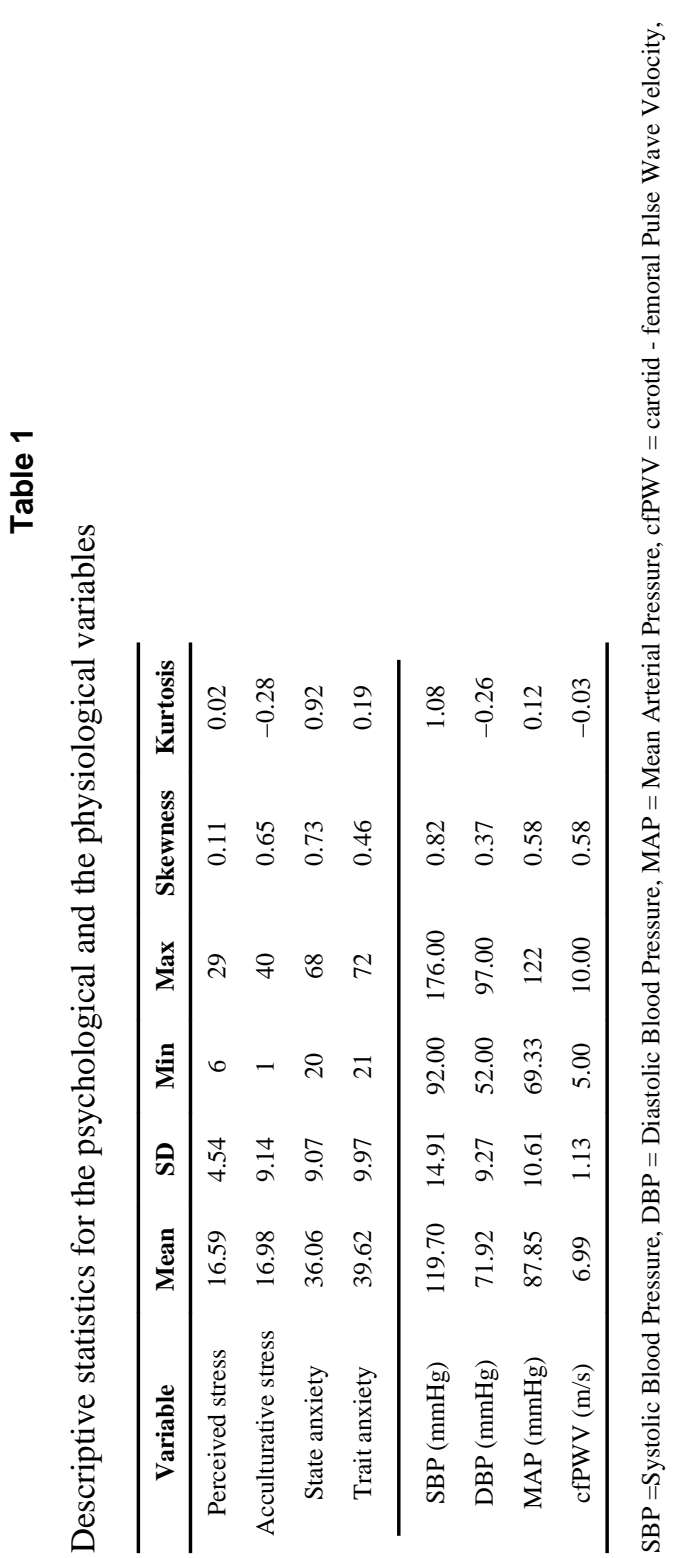


Table 2

Correlation of Arterial Stiffness and Blood Pressure with Psychological Stress Variables (n=102)

\begin{tabular}{ccccc}
\hline & cfPWV r(p) & SBP r(p) & DBP r(p) & MAP r(p) \\
\hline Perceived stress & $0.06(0.536)$ & $-0.02(0.821)$ & $0.03(0.763)$ & $0.01(0.945)$ \\
Acculturative stress & $0.19(0.046)$ & $0.20(0.045)$ & $0.13(0.204)$ & $0.17(0.093)$ \\
State anxiety & $0.30(0.002)$ & $0.20(0.044)$ & $0.18(0.074)$ & $0.19(0.047)$ \\
Trait anxiety & $0.21(0.030)$ & $0.09(0.367)$ & $0.06(0.566)$ & $0.08(0.448)$ \\
Anxiety * & $0.27(0.006)$ & $0.15(0.127)$ & $0.12(0.217)$ & $0.14(0.151)$ \\
\hline
\end{tabular}

One factor (anxiety) was created from state anxiety and trait anxiety by a principal components analysis. cfPWV $=$ carotid - femoral Pulse Wave Velocity, SBP =Systolic Blood Pressure, DBP = Diastolic Blood Pressure, MAP = Mean Arterial Pressure 
Table 3

Multiple regressions on arterial stiffness

\begin{tabular}{ccccc}
\hline Variable & $\boldsymbol{\beta}$ & $\mathbf{S E}$ & P value & Variance Inflation \\
\hline Age & 0.06 & 0.01 & $<.0001$ & 1.31 \\
MAP & 0.03 & 0.01 & 0.0003 & 1.25 \\
Education & 0.01 & 0.07 & 0.8724 & 1.29 \\
BMI & 0.04 & 0.03 & 0.0898 & 1.11 \\
Acculturative stress & -0.01 & 0.01 & 0.1684 & 1.39 \\
Anxiety & 0.25 & 0.09 & 0.0083 & 1.39 \\
\hline
\end{tabular}

R-Square $=.5282(\mathrm{~F}=17.36, \mathrm{P}<.0001)$

MAP $=$ Mean Arterial Pressure, $\mathrm{BMI}=$ Body Mass Index 